\title{
Simple method for identifying interdependencies in service delivery in critical infrastructure networks
}

\author{
A. E. Schweikert ${ }^{1 \dagger}$, G. F. L'Her ${ }^{2 \dagger}$ and M. R. Deinert ${ }^{1 *}$ (D)
}

\author{
*Correspondence: \\ mdeinert@mines.edu \\ ${ }^{\dagger}$ A. E. Schweikert and G. F. \\ L'Her contributed equally to \\ this work. \\ ${ }^{1}$ Department of Mechanical \\ Engineering, Payne Institute \\ for Public Policy, The \\ Colorado School of Mines, \\ Golden, USA \\ Full list of author information \\ is available at the end of the \\ article
}

\begin{abstract}
Critical infrastructure failures from natural hazard events affect the economic and social well-being of communities. This is particularly true in lower income countries, where infrastructure may be less resistant to natural hazards and disaster recovery is often limited by available resources. The interconnectivity of these systems can strongly affect the services they deliver, and the failure of one infrastructure system can result in cascade failures with wide-reaching consequences. Unfortunately, interconnectivity has been particularly difficult to measure. We present a method for identifying serviceoriented interdependencies in interconnected networks. The approach uses wellestablished methods for network analysis and is demonstrated for healthcare services in the Commonwealth of Dominica, a small island state in the Caribbean. We show that critical links in road networks necessary for healthcare service delivery are important for more than just patient access to a facility, but also on the supply chains that enable the hospitals to function (e.g., water, fuel, medicine). Once identified, the critical links can be overlaid with known hazard vulnerabilities to identify the infrastructure segments of highest priority, based on the risk and consequences of failure. An advantage of the approach presented is that it requires relatively little input data when compared to many network prioritization models and can be run using open-source geospatial data such as OpenStreetMap. The method can be expanded beyond road networks to assess the service-oriented criticality of any infrastructure network.
\end{abstract}

Keywords: Critical infrastructure, Climate change, Natural hazards, Network analysis, Criticality, Facilities impact, Disaster risk management, Planning

\section{Introduction}

The value of critical infrastructure systems is directly related to the services they provide and enable. A key vulnerability of these systems is the damage to, or failure of, system components during and following natural hazard events. In 2017, global economic losses related to natural hazard events are estimated to have been $\sim \$ 337$ billion, with less than half of this insured (Swiss Re 2018). These direct impacts are expensive and result in part from the failure of critical infrastructure systems including roads, railways, transmission infrastructure, buildings and other assets. Indirect impacts such as loss of income, disruption of supply chains and injuries and morbidity, among other factors, author(s) and the source, provide a link to the Creative Commons licence, and indicate if changes were made. The images or other third party material in this article are included in the article's Creative Commons licence, unless indicated otherwise in a credit line to the material. If material is not included in the article's Creative Commons licence and your intended use is not permitted by statutory regulation or exceeds the permitted use, you will need to obtain permission directly from the copyright holder. To view a copy of this licence, visit http:// creativecommons.org/licenses/by/4.0/. 
add to these costs. Particularly in lower income economies and vulnerable regions including small island states, the increased societal impacts are often exacerbated (Hallegatte et al. 2019a, b). Between 2000 and 2015, natural hazards are estimated to globally have caused over 700,000 deaths, the loss of homes for more than 23 million people, and impacted more than 1.5 billion (UNISDR 2015). A recent World Bank study estimated these impacts as well as those resulting from climate change at \$391-647 billion for households and firms annually in low- and middle-income countries (Hallegatte et al. 2019a, b).

In recent years, techniques from the study of complex adaptive systems have been used to help understand networked infrastructure systems. This is particularly true for power systems, although the principles and approach can be extrapolated to other critical infrastructure systems (van der Merwe et al. 2018). The systems perspective has been recognized as a key element to empower communities to address unknown challenges (Linkov and Trump 2019). A hallmark of resilient infrastructure systems is their ability to deliver services during and after hazard events (Hallegatte et al. 2019a, b). An existing challenge is the ability to measure and identify the most critical components within a system, especially when multiple infrastructure systems are interdependent.

Recent reviews from multiple domains have focused on quantitative methods for assessing infrastructure vulnerability and resilience. Mattsson and Jenelius (2015) provide a review of work in the transportation network field, specifically looking at resilience analyses related to transportation systems. They identify two areas of divergent research methods. First, topological network assessments rooted in graph theory that can identify important properties of failure and be transferred across different systems. Conversely, the second approach focuses on behavior, including the supply and demand impacts resulting from models of the transport system. The latter is recognized for capturing a better picture of the system but requires more data and more computational time. The need for cross-disciplinary research is emphasized as research proliferates (Mattsson and Jenelius 2015; Taylor and D'Este 2007). A recent analysis of transportation network perturbations from climate and hazard-induced loss and the impacts to agriculture in Vietnam can be found in Eun Oh et al. (2019). In power systems, similar assessments have been done, heavily focused on modeling approaches applied to synthetic and/or simplified networks. Baldick et al. 2009 (Baldick et al. 2009) reviews methods for modeling vulnerability assessments and cascading failures in power systems. A review specific to the impacts of natural hazards on power systems can be found in Wang et al. (2016). Panteli and Mancarella (2015) review extreme weather events on power system transmission networks and propose methods for future research including resilience attributes of network assessment. Salman and Li (2018) look at the resilience of power grids, including identifying the importance of individual links relative to the prevalence of blackout occurrences. Many of these studies build on a 2007 book (Murray and Grubesic 2007) that gives an overview of many different methods and questions in the context of critical infrastructure reliability and vulnerability.

Network analysis methods used to study infrastructure include drop-link assessments, application of criticality metrics, agent-based modeling approaches and network perturbation techniques with which to understand things like targeted attacks. Agent-based methods model the interactions between autonomous agents (people, 
households, diseases) based on specified behaviors. They have been used to understand the flow of people and goods following acute hazards along specific transportation networks (e.g. Mostafizi et al. 2017; Hilljegerdes and Augustijn-Beckers 2019). A recent study of supply chain disruptions in Tanzania from flooding hazards identified critical road links based on multiple priorities using input-output economic models resulting from agent (firm) behaviors (Colon et al. 2021). More information on the methodology and several examples across domains can be found in (Bonabeau 2002). A limitation of agent-based modeling is that it requires substantial input information to be available about the system and its components. When this detailed information about agent behavior is available, it is a powerful tool to identify emergent behaviors in large population assessments.

Drop-link assessments typically measure the impacts of single or multiple link loss on overall network function between origin-destination pairs. Previous work in this domain includes assessment of the most critical road links between cities in Australia (Taylor and D'Este 2007), which is similar to the perturbation methods developed for this study. Similar link importance methods have been used on a simplified Swedish road network (Jenelius et al. 2006) and at specific transport corridors in the United States looking at employer-household travel patterns (Kermanshah and Derrible 2017). To date, a limitation of many studies is the ability to run on real, often very large, infrastructure network data, resulting in studies of simplified and/or synthetic networks. An exception to this is found in Ganin et al. (2017) which assessed the fragility of road networks in 40 urban areas in the United States to perturbations and link loss.

One output of drop-link analyses is a 'criticality' metric. The definition of criticality varies by study, but generally criticality is the value of a network segment relative to the overall network function. One recent study (Espinet Alegre et al. 2020) focused on how network perturbations affect the delivery of and/or access to specific services using a least-cost travel model. This study focused on measuring access to economic and health facilities in Cambodia and highlights the value of specific, service-oriented analysis metrics to inform decision making. When defined as a permanent network property using centrality and betweenness methods, criticality identifies the most connected and/ or highest capacity nodes of the overall network (e.g.: Hawick and James 2007; Saleh et al. 2018; Li and Kao 2008). In other studies (including this one), criticality is defined as a performance metric specific to origin-destination pairings (e.g., Hilljegerdes and Augustijn-Beckers 2019; Mostafizi et al. 2017; Taylor and D'Este 2007; Jenelius et al. 2006; Kermanshah and Derrible 2017).

Answering specific questions about infrastructure segment criticality, service delivery, and impacts to populations in hazard situations have been assessed using multiple methods (e.g., Murray and Grubesic 2007). This is heavily emphasized in recent work in the context of developing countries, noting that the choice of metric used to assess priorities can drastically change the results (Hallegatte et al. 2019a, b). The interconnectivity of infrastructure systems can strongly affect the services they deliver, and the failure of one infrastructure can result in cascade failures with wide-reaching consequences. Although widely recognized as a serious concern, how to mitigate the risks posed by infrastructure interdependency and complexity remains a nascent area of research. With few exceptions, even quantifying the linkages between infrastructures, their interdependencies, 
or failure mechanisms, is rarely done (e.g., Helbing 2013; Little 2002; World Economic Forum 2011).

Here we present a method for using drop-link analysis to show the interconnectivity of service delivery and road networks. We consider three essential services that are inputs (water, power and people) necessary for hospital operation (e.g., FEMA 2007) and determine the set of critical road network segments relative to them. The intersections of these sets identify road links that, when removed, cause a cascade effect on the supply of important services. The supply services examined include potable water supply (backup water in times of damage to water transmission system and/or drought conditions), reliance on imported materials at seaports (medicine, diesel fuel) and patient access to hospitals. Results are presented for the Commonwealth of Dominica, a small island in the Caribbean vulnerable to multiple natural hazard events. The water delivery assessment is important because Dominica has a significant dry season and potable water transmission and distribution systems can be damaged by hurricanes, a significant risk in the region. Dominica also has multiple water areas that are served by tank trucks during these events (Dominica Water and Sewerage Company Limited (DOWASCO) $2020 \mathrm{a}, \mathrm{b})$. The delivery of fuel from ports to power plants is assessed because the majority of electricity generated on the island is from imported liquid fuels, including diesel (National Renewable Energy Lab (NREL) 2015). The delivery of imported materials to the hospitals is assessed because of the geography of the island, relying heavily on imported goods including diesel fuel (for backup generators onsite) and medical materials such as medicine. A virtue of this method, especially in the developing regions, is that it can be implemented with relatively sparse data (i.e., OpenStreetMap) and open source tools (i.e. Python, PostgreSQL). The results are important for understanding how to best allocate limited resources for resiliency planning.

\section{Methods}

A network of nodes and edges is used to connect user-defined origin and destination pairs in a road system. A drop-link analysis of the impact to service delivery for four different road priorities (household travel to hospitals, imported fuel delivery to power plants, imported fuel and supply delivery to on-site hospital generators, water supply from treatment centers to hospitals) was done. The travel costs associated with dropped links are determined using a single-source, shortest-path Dijkstra algorithm, which finds shortest paths between nodes in a graph (Dijkstra 1959; Fredman and Tarjan 1987; pgRouting 2021), Additional file 1: Note 1 . The set of critical road network links are determined relative to healthcare service delivery. The intersection of these sets gives the links ("segments") whose removal causes failures to cascade across multiple services and health care delivery in particular. The most critical road segment map is overlaid with a real hazard map to illustrate how the information can inform policy specific to the risk of road failure resulting from exposure and consequence.

\section{Network approach}

A network of nodes and edges is used to connect user-defined origin and destination pairs in a networked infrastructure system. The relative value of each network segment measured as the impacts that perturbations have on overall performance and 
connectivity, is determined using drop-link analysis. The impacts of perturbations are defined as the increase in travel costs (time), determined using the Dijkstra algorithm (Dijkstra 1959). A reference run computes the aggregate costs between every origin and destination pairs within the entire unperturbed network. The impact of the removal of any segment(s) is then computed by recalculating the origins-destinations aggregate costs in the updated network. Segment criticality is determined in terms of travel cost between origin and destination pairs. 'Criticality' is defined as the cost of dropping a network segment on travel times between all origin and destination pairs (every segment is dropped once, and travel cost is calculated over entire network routing). The impact is defined by the difference between 'normal' and 'perturbed' network matrices of travel cost between all origin and destination pairs, calculated over the entire drop-link segment analysis.

In this analysis, the road network is split into segments of $100 \mathrm{~m}$, along with remainder and/or shorter length segments where appropriate. This results in the $860 \mathrm{~km}$ of roads in Dominica (223 km Primary, $58 \mathrm{~km}$ Secondary, $236 \mathrm{~km}$ Tertiary and $341 \mathrm{~km}$ Local Roads) split into over 10,000 individual segments for analysis. Ancillary infrastructure such as bridges are treated as individual segments in the network.

\section{Service delivery}

Three inputs necessary for hospital operation were assessed individually: water, people and electricity (proxy analysis of diesel fuel availability at the power plants). Four road criticality sets are generated: household travel to hospitals, water delivery from water treatment centers to hospitals, fuel delivery from ports to power plants, and backup fuel and medical supply delivery from ports to hospitals. The location of all facilities including water and wastewater treatment facilities, health centers, and households comes from a combination of local data sources, country reports, OpenStreetMap, Google queries, and the World Bank CHARIM datasets (ACP-EU Natural Disaster Risk Reduction Program, n.d.; Schweikert et al. forthcoming). Ports data is from the National Geospatial Intelligence Agency (National Geospatial Intelligence Agency 2019). Power plant data was collected from the Global Power Plant Database (World Resources Institute 2019) and augmented with specific research by the authors (Schweikert et al. forthcoming).

The set of critical road segments for travel between each origin and destination pair is assessed. For patients, travel between all households (approximately 20,000) on the island (origins) and the three health center facilities (destinations) is assessed. The set of critical road segments for water delivery was determined for travel between all water treatment centers (origins) and the three hospitals (destinations). The set of critical road segments for fuel supply was assessed for travel between two ports (origins) to the major power plants (destinations). Finally, travel between the ports (origins) and health centers (destinations) was assessed to identify the supply chain for imported materials including medical supplies and diesel fuel for the backup generators.

The overall criticality map for each of the four origin-destination pairs described above is created by assessing the number of times a road segment appears in the highest quintile ("Q5") of importance (these are the segments that, if dropped, have the highest impact on overall travel cost in the network). Then, these four maps are combined to determine the intersections of segments that are considered most critical (Q5). In the 
combined criticality analysis, an equal weighting is used. This is a user-defined choice and could be easily changed based upon local knowledge and preferences. These locations of high criticality identify locations where the delivery of multiple services would be highly impacted if this road segment is disrupted. The intersection of the individual criticality assessments of road segments determines the interdependencies between services, as these intersecting locations would disrupt multiple services if perturbed.

\section{Assessment of hazard exposure}

The criticality sets, and their intersections, can be overlaid with specific hazard maps, such as flooding. This combination of exposure identifies the highest priority areas for interventions such as hardening. Here, the 0.02 -annual probability event ("50-year flood event") was used to examine the potential impact for combined hazards of fluvial, pluvial and coastal surge flooding. Three geospatial flooding data sets (fluvial, pluvial and coastal surge) (Deltares 2020) and engineering-based flooding fragility curves (Espinet Alegre et al. 2020; Koks et al. 2019) were used to determine road segments where flooding would exceed operational thresholds.

\section{Results}

The interconnectivity of multiple services required for healthcare operations at hospitals in the Commonwealth of Dominica includes delivery of water, fuel for electricity, imported supplies and patients. An assessment of road segment criticality for the delivery of each input service required for hospital operations is assessed using drop-link analysis. Results for each service, measured independently, are shown in Table 1 and Figs. 1 and 2. Table 1 gives the total length of roads of each type (primary, secondary, tertiary, and local) calculated as most critical (5th quintile or "Q5"). Figure 1 shows results for the entire island for delivery of water, imported supplies, fuel for electricity, and patients, while Fig. 2 is focused on the Roseau area. The results show marked differences in road segment criticality depending upon the perspective

Table 1 Length of road segments classified in the most critical quartile ("Q5") for each supply chain, and percent for each road type relative to total road length

\begin{tabular}{|c|c|c|c|c|c|c|c|c|}
\hline \multirow[t]{2}{*}{ Perspective } & \multicolumn{2}{|c|}{ Primary roads } & \multicolumn{2}{|c|}{ Secondary roads } & \multicolumn{2}{|c|}{ Tertiary roads } & \multicolumn{2}{|c|}{ Local roads } \\
\hline & $\begin{array}{l}\text { Length in } \\
\text { Q5 (m) }\end{array}$ & $\begin{array}{l}\text { Percent } \\
\text { of } \\
\text { Primary } \\
\text { Roads }\end{array}$ & $\begin{array}{l}\text { Length in } \\
\text { Q5 (m) }\end{array}$ & $\begin{array}{l}\text { Percent of } \\
\text { Secondary } \\
\text { Roads }\end{array}$ & $\begin{array}{l}\text { Length in } \\
\text { Q5 (m) }\end{array}$ & $\begin{array}{l}\text { Percent } \\
\text { of } \\
\text { Tertiary } \\
\text { Roads }\end{array}$ & $\begin{array}{l}\text { Length in } \\
\text { Q5 (m) }\end{array}$ & $\begin{array}{l}\text { Percent } \\
\text { of Local } \\
\text { Roads }\end{array}$ \\
\hline $\begin{array}{l}\text { [1] House- } \\
\text { holds to } \\
\text { Hospitals }\end{array}$ & 22,554 & 10.1 & 18,020 & 30.7 & 45,288 & 19.1 & 70,090 & 20.6 \\
\hline $\begin{array}{l}\text { [2] Water } \\
\text { Treatment } \\
\text { to Hospitals }\end{array}$ & 28,455 & 12.7 & 13,476 & 22.9 & 24,232 & 10.2 & 5,652 & 1.7 \\
\hline $\begin{array}{l}\text { [3] Seaports } \\
\text { to Hospitals }\end{array}$ & 3,031 & 1.4 & 0 & 0 & 0 & 0 & 194 & 0.1 \\
\hline $\begin{array}{l}\text { [4] Seaports } \\
\text { to Power } \\
\text { Plants }\end{array}$ & 25,403 & 11.4 & 0 & 0 & 300 & 0.1 & 0 & 0 \\
\hline All Roads [m] & 223,746 & & 58,782 & & 236,835 & & 341,063 & \\
\hline
\end{tabular}




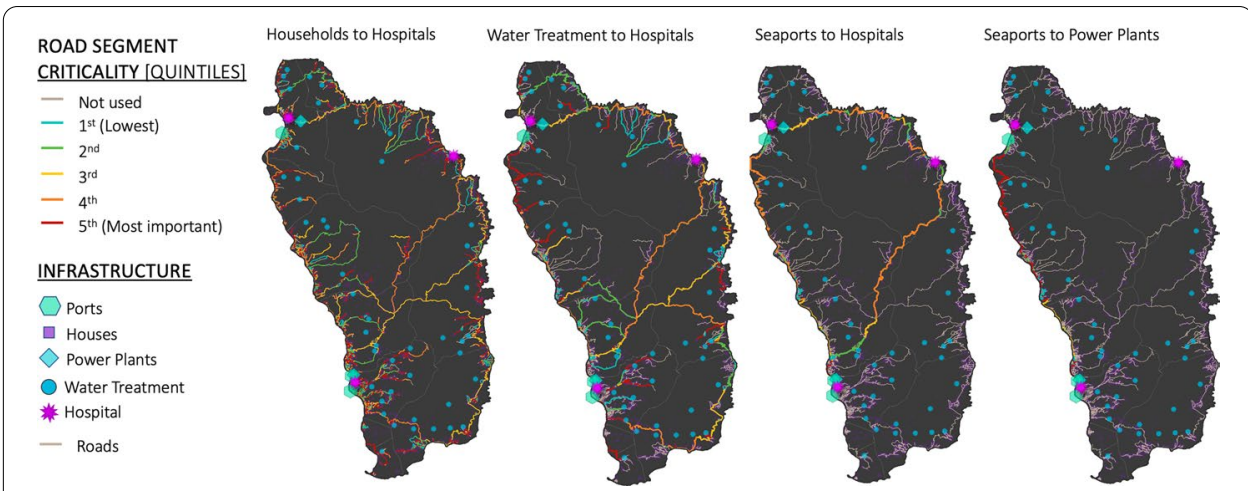

Fig. 1 Road segment criticality shown in quintiles. Criticality is calculated using drop-link analysis. More critical segments indicate that the loss of this segment increases overall travel cost for the origin-destination pair in each perspective
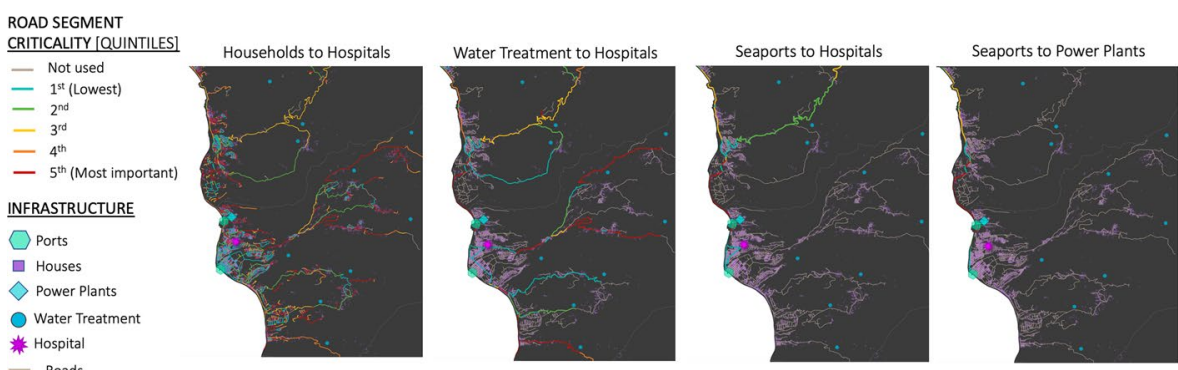

Fig. 2 Road segment criticality shown in quintiles. Criticality is calculated using drop-link analysis. More critical segments indicate that the loss of this segment increases overall travel cost for the origin-destination pair in each perspective. Results shown for Roseau region

chosen, highlighting the importance of considering these locations of interconnectivity across multiple services. The computational time for the different scenarios and combinations of nodes (origins and destinations) and links (network segments) is provided in Additional file 1: Note 1.

For patient access to hospitals, the greatest number of nodes is used, with over 20,000 households and three health center destinations. Approximately $22.5 \mathrm{~km}$ of primary road ( $>10 \%$ of all primary roads) fall into the highest category of criticality (Q5), while over $30 \%$ of secondary roads, almost $20 \%$ of tertiary roads and $20 \%$ of local roads are in Q5 for service delivery (hospital access). Many roads in the $5^{\text {th }}$ quintile are residential routes for which there are no redundant options. The failure of these segments means that the overall travel times increase substantially compared to the loss of other segments.

For water delivery to hospitals, $28 \mathrm{~km}$ of primary road are considered critical, representing almost $13 \%$ of all primary roads. $23 \%$ of secondary roads are highly critical for service delivery, while $10 \%$ of tertiary roads are, and less than $2 \%$ of local roads. This is because the travel from inland water treatment plants relies on non-redundant roads and their loss eliminates the travel potential. The major highway transecting the island has many segments classified in the $3^{\text {rd }}$ or $4^{\text {th }}$ quintile for multiple services, 
including water and patient travel. While these are not the focus of this analysis (looking at Q5 only), this indicates that loss of one or more segments on this main thoroughfare would require costly, though possible, re-routing around the island.

Fuel delivery from ports to power plants has the smallest number of critical road segments. This is because both of the power plants and ports sit on the western side of the island, near the coast, with reduced travel distances compared to delivery of people, imported supplies and water to hospitals. The delivery of fuel from seaports to power plants is most critical along primary roads, affecting just under $2 \%$ of the network, Table 1.

Once the criticality of each road segment is established for each individual service delivery, a combined criticality metric is calculated to identify the road segments indicating interconnectivity and dependency for service delivery, Fig. 3. These results are also shown in Table 2 . Overall, there is $0.71 \mathrm{~km}$ of primary road that is identified as the most critical for all four services. While this represents only $0.3 \%$ of the total primary road network, the loss of these segments would have very substantial impacts on overall healthcare delivery, as access to hospitals for patients, fuel delivery for electricity production, imported supply delivery and water delivery in times of drought would all be disrupted. Nearly $20 \%$ of the secondary road network is considered highly critical for two supply chains. The results presented in Table 2 show that there are very few road segments that have overlapping service delivery interconnectivity,

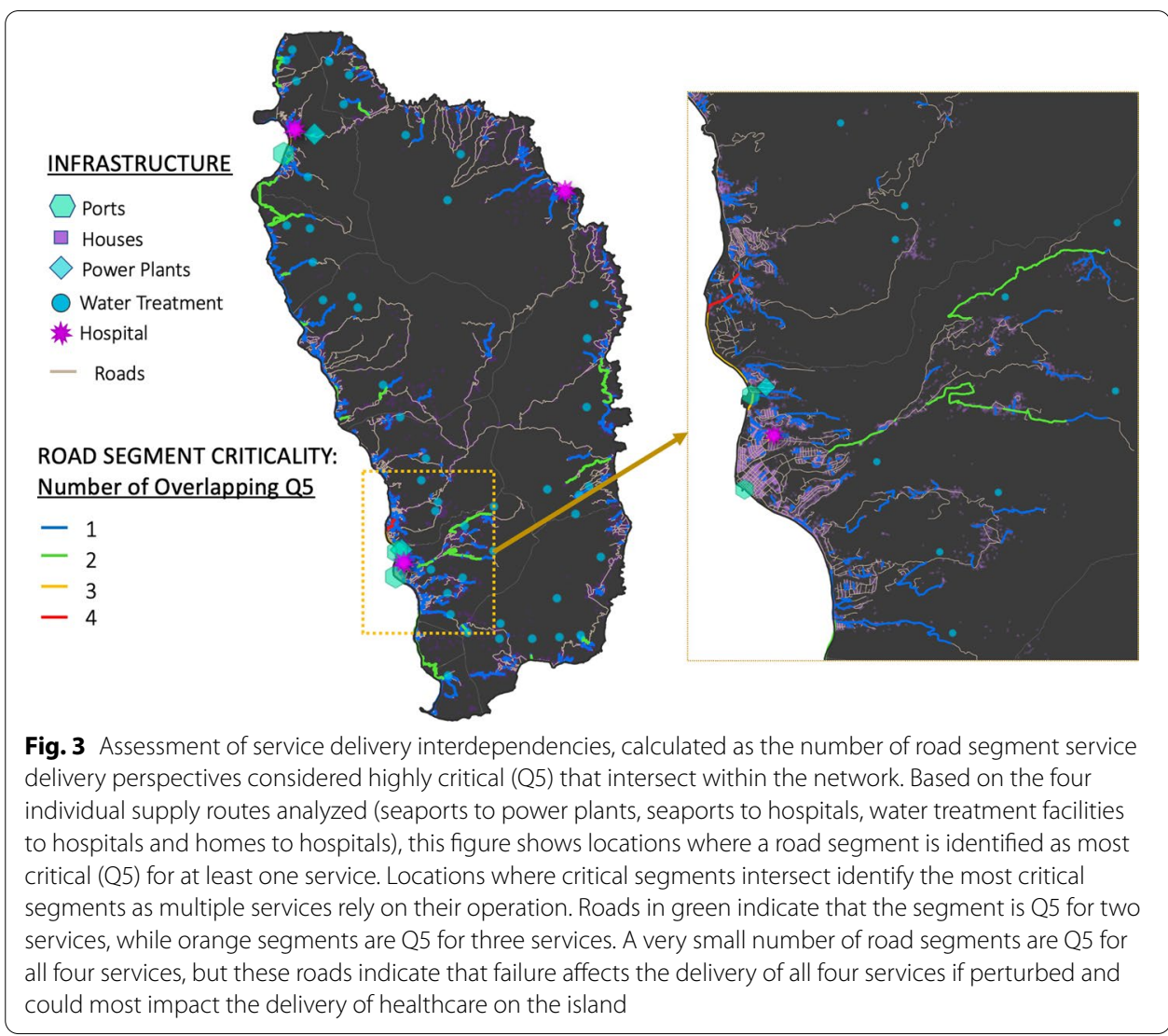


Table 2 Length of road segments classified in the most critical quintile ("Q5"), based on the number of scenarios

\begin{tabular}{lcllllllc}
\hline Road type & 1_Q5 [m] & 1_Q5 [\%] & 2_Q5 [m] & 2_Q5 [\%] & 3_Q5 [m] & 3_Q5 [\%] & 4_Q5 [m] & 4_Q5 [\%] \\
\hline Primary & 27,282 & 12 & 21,179 & 9.5 & 2,321 & 1.0 & 710 & 0.3 \\
Secondary & 9,338 & 16 & 11,079 & 18.8 & & - & & - \\
Tertiary & 47,069 & 20 & 11,375 & 4.8 & & - & & - \\
Local & 71,798 & 21 & 1,778 & 0.5 & 194 & 0.1 & & - \\
Total (all roads) & 155,487 & 18.1 & 45,411 & 5.3 & 2,515 & 0.3 & 710 & 0.1 \\
\hline
\end{tabular}

"1_Q5" indicates the length of road segments classified as most critical for only a single assessment; "2_Q5" indicates the length of road segments classified as most critical from two assessments; "3_Q5" indicates the length of road segments classified as most critical from three assessments; "4_Q5" indicates the length of road segments classified as most critical from all four assessments performed. Values are given in both meters and percent of total road network for each type

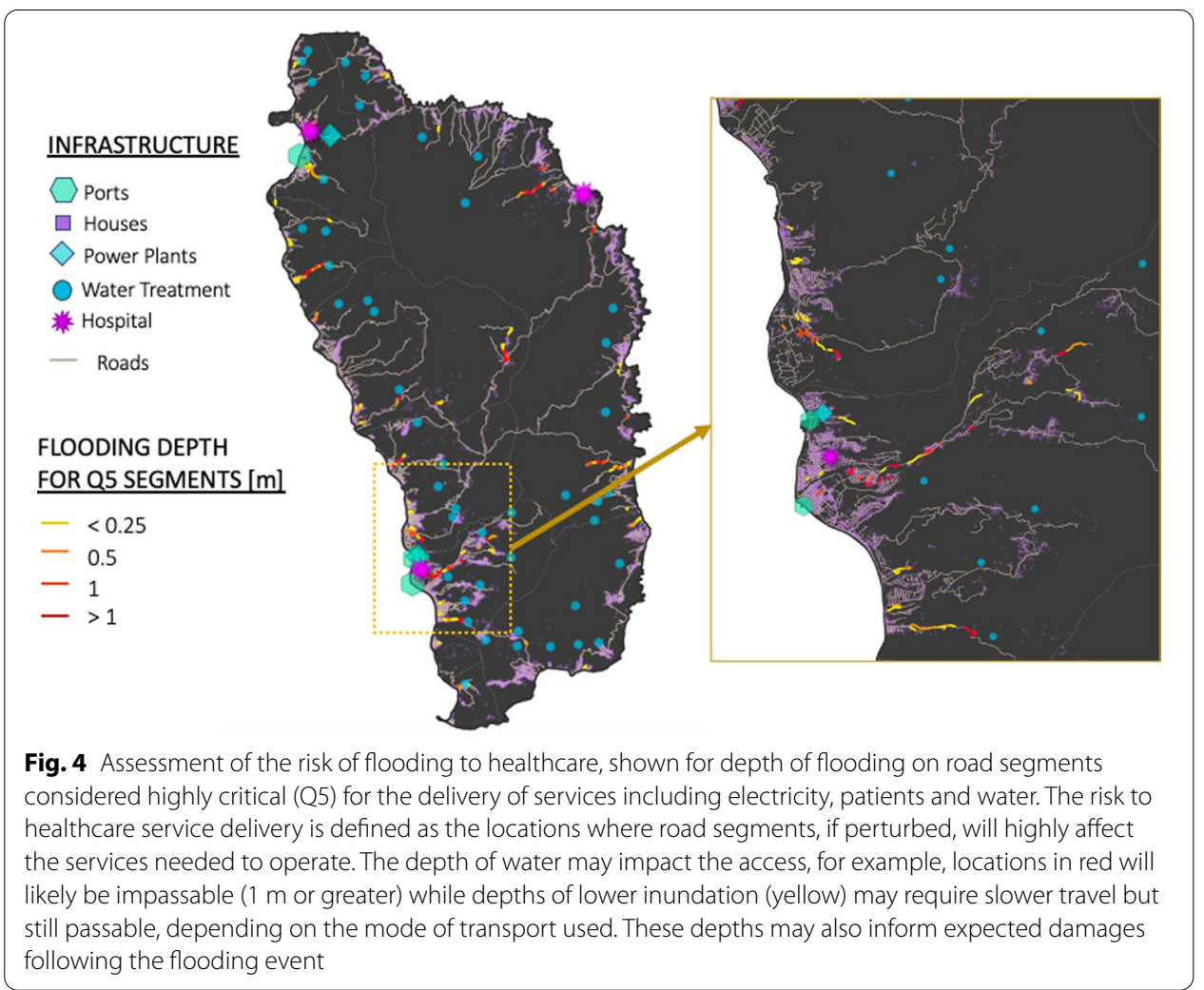

providing a focused analysis of the most important road segments for healthcare service delivery (as defined by the four individual criticality assessments).

The final analysis is to use the shock-agnostic map of the most critical network locations from healthcare services delivery to see where the impacts are most likely to be exposed to a hazard event. In this analysis, the 0.02 -annual probability flooding event ("50-year") was chosen. Figure 4 shows where Q5 road segments, for at least one service delivery, are exposed to flooding of different depths. Where hazard-specific data on damages, costs and times to repair, and other data is available, this can help inform planning. For example, floods depths exceeding $1 \mathrm{~m}$ may lead to much longer recovery times and higher costs than locations with low levels of flooding. The map shown 
in Fig. 4 identifies the greatest vulnerabilities along mountain roads from the inland allowing access towards healthcare facilities. The total Q5 road segments exposed to flooding of various depths is listed in Table 3. For the 0.02-annual probability flooding event, none of the most critical locations in the road network - those with 3 or 4 overlapping perspective criticality values of Q5 - are exposed. Eleven percent of the locations where 2 services are dependent upon the segment are exposed to flooding of some depth, the majority $(\sim 4,000 \mathrm{~m})$ at a depth of $0.5 \mathrm{~m}$ or less. Seventeen percent of the segments where one input service contributing to healthcare service delivery is rated as Q5 are exposed to flooding of some depth. While the majority are at a depth of $0.25 \mathrm{~m}$ or less (over $10 \mathrm{~km}$ ), over $5 \mathrm{~km}$ is exposed to depths exceeding one meter, which is likely to cause damages and thus disruptions persisting beyond the actual flooding event.

\section{Discussion}

Networked infrastructure plays a critical role in underpinning the function of modern societies. However, an analysis of these networks with a single supply chain or perspective will often mask network segments that are important to the delivery of key services that rely upon multiple services delivered through multiple networks. Evaluating the interconnectivity between critical infrastructures (such as the power grid and transportation networks), or the services they deliver (power, water, etc.), is still a nascent area of quantitative research. An important initial step in identifying the likelihood that key services (e.g., healthcare) are disrupted during a shock event is identifying how these services rely on other networks (e.g., roads). Drop-link analysis is ideal for this purpose. By expanding this approach to identify the critical segments of a single network from multiple perspectives (in this case, the inputs of water, electricity, imported medical supplies and patients), the interdependencies of these services on a single network can be determined. This information is shock-agnostic, providing a map of network segments that are relatively more important for the delivery of essential services. This information can be used in a variety of ways for decision making, including overlaying with exposure maps for identified hazards in a region to identify the highest priority segments for hardening or other mitigation options.

An area to which the methods presented here could be extended is to apply the results to inform cost-benefit analysis between different hazard planning options. This study illustrates how to identify key network segments for hardening or other mitigation options. When hazards are identified, specific shocks to the network using failure

Table 3 Length of road segments classified in the most critical quartile ("Q5") and exposed to flooding during the 0.02-annual probability event ("50-year flood")

\begin{tabular}{lllllllll}
\hline Flood Depth [m] & 1_Q5 [m] & 1_Q5 [\%] & 2_Q5 [m] & 2_Q5 [\%] & 3_Q5 [m] & 3_Q5 [\%] & 4_Q5 [m] & 4_Q5 [\%] \\
\hline$<0.25$ & 10,338 & 1.2 & 2,409 & 0.3 & - & - & - & - \\
$0.25-0.5$ & 5,731 & 0.7 & 1,451 & 0.2 & - & - & - & - \\
$0.5-1$ & 4,896 & 0.6 & 533 & 0.1 & - & - & - & - \\
$>1$ & 5,222 & 0.6 & 400 & 0.0 & - & - & - & - \\
Any flood depth & 26,187 & 3.0 & 4,792 & 0.6 & - & - & - & - \\
\hline
\end{tabular}

Values are aggregated for all road types 
probabilities could quantify specific case studies of the impacts of perturbations. Monte Carlo simulation could then identify the expected change, for example, in patient influx at different healthcare centers due to rerouting. It could also identify the expected delay in fuel delivery to power plants and/or hospital facilities. These inputs could provide valuable information about the stockpiling of supplies, fuel, and other resources at hospitals to account for failures within the road network. The costs for hardening roads or bridges and for stocking fuel or supplies are very different, and in some regions may be more or less feasible compared to alternatives.

Further extensions of this work include analysis of other assets, such as the seaports, which could be damaged in a hazard event. In Dominica, this supply chain analysis is critical because, while ongoing investments in renewable energy sources are being made, as of 2015 over $70 \%$ of the electricity supply is powered by Diesel fuel (National Renewable Energy Lab (NREL) 2015). Damages to ports and roadways resulting from hazard events can drastically reduce the ability of imported fuel supply chains to continue functioning. For hazards that cause widespread damages, such as hurricanes, assessing how imported goods can be delivered throughout the island can inform broader recovery plans as well. The ability to inform cost-benefit assessments with specific quantitative results can enhance emergency planning, preparedness and investments across communities including prioritization of the most cost-effective interventions based on specific goals. Future work could also consider congestion (traffic, in the context of road networks) resulting from the perturbed network scenarios. This consideration is especially important in hazard scenarios or on infrastructure such as power systems where overloading can result in cascading network failures. A limitation here is the available data, although methods for estimation may be useful.

An advantage of the approach presented here is that it is flexible for application across different types of networks. The computational time for a single origin destination pair scales as $\mathrm{O}(\mathrm{E}+\mathrm{V} \log \mathrm{V})$, where $\mathrm{V}$ is the number of nodes in the network and $\mathrm{E}$ the number of edges (pgRouting 2021). The computational time then scales linearly with the number of origins going to a particular destination, Additional file 1: Table S1, and linearly with the number of edge perturbations (see Additional file 1 for additional details). The algorithms for assessing the impacts to the network and resulting impacts to critical facilities or supply chain impacts are inherently agnostic to the network, origins, destinations, hazards and costs defined by the user. It is based on open-source software platforms including Python, QGIS and PostgreSQL.

\section{Conclusions}

This paper presents a method to provide multi-sectoral insight into the impacts of network perturbations on connected systems and critical facilities and is demonstrated using geospatial infrastructure and natural hazard data for the Commonwealth of Dominica. The interdependencies of different types of services on a single infrastructure can be determined using drop-link analysis. These overlapping interdependencies highlight the interconnected nature of service delivery. An orientation of service delivery can help inform different perspectives for investments, cost-benefit analysis and policy making. The method presented is flexibly designed for user-defined input parameters including geospatial data (origins, destinations, network), hazard exposure, infrastructure fragility, 
and repair times for damaged assets. This approach is particularly important because of the interconnected nature of infrastructure systems and communities, especially in times of hazard occurrence and other emergencies.

\section{Supplementary Information}

The online version contains supplementary material available at https://doi.org/10.1007/s41109-021-00385-4.

Additional file 1. Supplementary information.

Acknowledgements

Special thanks to Julie Rozenberg for discussions of resilience in small island states.

\section{Authors' contributions}

AS, GL and MD contributed to the conception, design, and analysis of the data presented here. GL created the software used for analysis and discussed in this paper. AS, GL, MD contributed to the interpretation of the data and to the writing and revisions of the manuscript. All author read and approved the final manuscript.

\section{Funding}

This work was partially funded by the World Bank, through the CARIBBEAN REGIONAL RESILIENCE BUILDING FACILITY funded by the European Union.

\section{Data Availability}

Some or all data, models, or code that support the findings of this study are available from the corresponding author upon reasonable request.

\section{Declarations}

\section{Competing interests}

The authors declare that they have no competing interests.

\section{Author details}

${ }^{1}$ Department of Mechanical Engineering, Payne Institute for Public Policy, The Colorado School of Mines, Golden, USA

${ }^{2}$ Nuclear Science and Engineering, Colorado School of Mines, Golden, USA.

Received: 15 January 2021 Accepted: 2 June 2021

Published online: 12 June 2021

\section{References}

ACP-EU Natural Disaster Risk Reduction Program (n.d.) Caribbean Handbook on Risk Management | CHARIM. Retrieved 5 May 2020, from http://charim.net/

Baldick R, Chowdhury B, Dobson I, Dong Z, Gou B, Hawkins D, Huang Z, Joung M, Kim J, Kirschen D, Lee S, Li F, Li J, Li Z, Liu C-C, Luo X, Mili L, Miller S, Nakayama M et al (2009) Vulnerability assessment for cascading failures in electric power systems. In: 2009 IEEE/PES power systems conference and exposition, pp 1-9. https://doi.org/10.1109/PSCE. 2009.4839939

Bonabeau E (2002) Agent-based modeling: Methods and techniques for simulating human systems. Proc Natl Acad Sci 99(suppl 3):7280-7287. https://doi.org/10.1073/pnas.082080899

Colon C, Hallegatte S, Rozenberg J (2021) Criticality analysis of a country's transport network via an agent-based supply chain model. Nat Sustain 4(3):209-215. https://doi.org/10.1038/s41893-020-00649-4

Deltares (2020) Assessing the impact of sea level rise potential in the Caribbean [Technical Report]

Dijkstra EW (1959) A note on two problems in connexion with graphs. Numer Math 1(1):269-271. https://doi.org/10. 1007/BF01386390

Dominica Water and Sewerage Company Limited (DOWASCO) (2020a, January) Water Area 1. https://www.dowasco.dm/ water_areas/waterarea1.pdf

Dominica Water and Sewerage Company Limited (DOWASCO) (2020b, January) Water System Areas. https://www.dowas co.dm/index.php/our-services/waterservice?id $=53$

Espinet Alegre X, Stanton-Geddes Z, Aliyev S, Bun V (2020) Analyzing flooding impacts on rural access to hospitals and other critical services in rural Cambodia using geo-spatial information and network analysis. World Bank, Washington, DC. https://doi.org/10.1596/1813-9450-9262

Eun Oh J, Espinet Alegre X, Pant R, Koks EE, Russell T, Schoenmakers R, Hall J (2019) Addressing climate change in transport. Volume 2: Pathway to Resilient Transport (Vietnam Transport Knowledge Series). The World Bank. http://docum ents.worldbank.org/curated/en/438551568123119419/pdf/Nolume-2-Pathway-to-Resilient-Transport.pdf

FEMA (2007) Design guide for improving critical facility safety from flooding and high winds (FEMA 543; Risk Management Series). Federal Emergency Management Agency. https://www.fema.gov/media-library-data/20130726-155720490-1542/fema543_complete.pdf 
Fredman ML, Tarjan RE (1987) Fibonacci heaps and their uses in improved network optimization algorithms. J ACM 34(3):596-615. https://doi.org/10.1145/28869.28874

Ganin AA, Kitsak M, Marchese D, Keisler JM, Seager T, Linkov I (2017) Resilience and efficiency in transportation networks. Sci Adv 3(12):e1701079. https://doi.org/10.1126/sciadv.1701079

Hallegatte S, Rentschler J, Rozenberg J (2019) Lifelines: the resilient infrastructure opportunity: Vol. English Overview. The World Bank Group. https://openknowledge.worldbank.org/bitstream/handle/10986/31805/211430ov.pdf?seque nce $=4 \&$ is Allowed $=y$

Hallegatte S, Rentschler J, Rozenberg J (2019) Lifelines: the resilient infrastructure opportunity (sustainable infrastructure). The World Bank. http://hdl.handle.net/10986/31805

Hawick KA, James HA (2007) Node importance ranking and scaling properties of some complex road networks. https:// mro.massey.ac.nz/handle/10179/4490

Helbing D (2013) Globally networked risks and how to respond. Nature 497(7447):51-59. https://doi.org/10.1038/natur e12047

Hilljegerdes M, Augustijn-Beckers E-W (2019) Evaluating the effects of consecutive hurricane hits on evacuation patterns in Dominica. ISCRAM

Jenelius E, Petersen T, Mattsson L-G (2006) Importance and exposure in road network vulnerability analysis. Transp Res Part a: Policy Pract 40(7):537-560

Kermanshah A, Derrible S (2017) Robustness of road systems to extreme flooding: using elements of GIS, travel demand, and network science. Nat Hazards: J Int Soc Prev Mitig Nat Hazards 86(1):151-164

Koks EE, Rozenberg J, Zorn C, Tariverdi M, Vousdoukas M, Fraser SA, Hall JW, Hallegatte S (2019) A global multi-hazard risk analysis of road and railway infrastructure assets. Nat Commun. https://doi.org/10.1038/s41467-019-10442-3

Li P-H, Kao J-J (2008) Segment-based vulnerability analysis system for a water distribution network. Civ Eng Environ Syst 25(1):41-58. https://doi.org/10.1080/10286600701838709

Linkov I,Trump BD (2019) The science and practice of resilience. Springer, Berlin. https://doi.org/10.1007/ 978-3-030-04565-4

Little RG (2002) Controlling cascading failure: understanding the vulnerabilities of interconnected infrastructures. J Urban Technol 9(1):109-123. https://doi.org/10.1080/106307302317379855

Mattsson L-G, Jenelius E (2015) Vulnerability and resilience of transport systems-a discussion of recent research. Transp Res Part a: Policy Pract 81:16-34. https://doi.org/10.1016/j.tra.2015.06.002

Mostafizi A, Wang H, Cox D, Cramer LA, Dong S (2017) Agent-based tsunami evacuation modeling of unplanned network disruptions for evidence-driven resource allocation and retrofitting strategies. Nat Hazards 88(3):1347-1372. https:// doi.org/10.1007/s11069-017-2927-y

Murray A, Grubesic T (eds) (2007) Critical infrastructure: reliability and vulnerability. Springer, Berlin

National Geospatial Intelligence Agency (2019) World Port Index, 27th Edition (Pub.150). United States Government. https://msi.nga.mil/api/publications/download?key=16694622/SFH00000/Pub150bk.pdf\&type=view

National Renewable Energy Lab (NREL) (2015) Energy Snapshot: Dominica (DOE/GO-102015-4580; Energy Transition Initiative). https://www.nrel.gov/docs/fy150sti/62704.pdf

Panteli M, Mancarella P (2015) Influence of extreme weather and climate change on the resilience of power systems: impacts and possible mitigation strategies. Electric Power Syst Res 127:259-270. https://doi.org/10.1016/j.epsr.2015. 06.012

pgRouting (2021) Djikstra Cost_Algorithm. https://docs.pgrouting.org/3.0/en/pgr_dijkstraCost.html

Saleh M, Esa Y, Mohamed A (2018) Applications of complex network analysis in electric power systems. Energies 11(6):1381. https://doi.org/10.3390/en11061381

Salman AM, Li Y (2018) A probabilistic framework for multi-hazard risk mitigation for electric power transmission systems subjected to seismic and hurricane hazards. Struct Infrastruct Eng 14(11):1499-1519. https://doi.org/10.1080/15732 479.2018.1459741

Schweikert A, L'her G, Deinert M (forthcoming) Resilience in the Caribbean: Natural Hazards Exposure Assessment and Areas for Future Work

Swiss Re (2018, April 10) At USD 144 billion, global insured losses from disaster events in 2017 were the highest ever, sigma study says. Swiss Re. http://www.swissre.com/media/news_releases/nr20180410_sigma_global_insured_ loses_highest_ever.html

Taylor MAP, D'Este GM (2007) Transport network vulnerability: a method for diagnosis of critical locations in transport infrastructure systems. In: Murray AT, Grubesic TH (eds) Critical infrastructure: reliability and vulnerability. Springer, Berlin, pp 9-30. https://doi.org/10.1007/978-3-540-68056-7_2

UNISDR (2015) Sendai Framework for Disaster Risk Reduction 2015-2030, p 37. United Nations Office of Disaster Risk Reduction

van der Merwe SE, Biggs R, Preiser R (2018) A framework for conceptualizing and assessing the resilience of essential services produced by socio-technical systems. Ecol Soc. https://doi.org/10.2307/26799110

Wang Y, Chen C, Wang J, Baldick R (2016) Research on resilience of power systems under natural disasters-a review. IEEE Trans Power Syst 31(2):1604-1613. https://doi.org/10.1109/TPWRS.2015.2429656

World Economic Forum (2011) Global risks 2011: an initiative of the risk response network. World Economic Forum. http://reports.weforum.org/wp-content/blogs.dir/1/mp/uploads/pages/files/global-risks-2011.pdf

World Resources Institute (2019, June) Global Power Plant Database—DatalWorld Resources Institute. https://datasets. wri.org/dataset/globalpowerplantdatabase

\section{Publisher's Note}

Springer Nature remains neutral with regard to jurisdictional claims in published maps and institutional affiliations. 